\title{
Monounsaturated fatty acids, olive oil and blood pressure: epidemiological, clinical and experimental evidence
}

\author{
Álvaro Alonso 1,2, Valentina Ruiz-Gutierrez ${ }^{3}$ and Miguel Ángel Martínez-González 1,* \\ 'Department of Preventive Medicine and Public Health, School of Medicine, University of Navarra, Irunlarrea 1, \\ ES-3 1008 Pamplona, Spain: ${ }^{2}$ Department of Epidemiology, Harvard School of Public Health, Boston, MA, USA: \\ ${ }^{3}$ Nutrition and Lipid Metabolism Group, Instituto de la Grasa (CSIC), Seville, Spain
}

Submitted 8 February 2005: Accepted 15 June 2005

\begin{abstract}
Diet has an important role in the prevention and treatment of hypertension. In early epidemiological studies, conducted mainly in the USA, monounsaturated fatty acids showed a deleterious association with blood pressure or no relationship at all. However, more recent studies, conducted in Mediterranean countries, have shed new light on this issue. In the present review we summarise the main results of epidemiological studies and feeding trials, and explain the possible mechanisms through which monounsaturated fatty acids, and specifically olive oil as the major dietary source of this type of fat in Mediterranean countries, could exert a favourable effect on blood pressure.
\end{abstract}

Diet plays an important role in the primary prevention of hypertension $(\mathrm{HT})^{1,2}$. Reduction of sodium and alcohol intake, an increase in potassium intake, and modification of the whole dietary pattern are the best-supported recommendations for the prevention of this disorder ${ }^{3,4}$. Based in an increasing amount of evidence, the classical Mediterranean dietary pattern has been proposed as a healthy choice for the prevention of cardiovascular disease $^{5}$. Part of its beneficial impact can be mediated through a favourable effect on blood pressure (BP) ${ }^{6}$. A major characteristic of the Mediterranean diet is a high supply of energy coming from monounsaturated fatty acids (MUFA), mainly from olive oil.

Laboratory data and results from epidemiological studies and clinical trials are accruing to support the importance of MUFA, and more particularly of olive oil, in the prevention of HT. In the present paper, we review the effect of MUFA and olive oil on BP levels and their possible role in the prevention and treatment of HT. Initially, we describe the epidemiological evidence linking MUFA, olive oil and BP. Then, we summarise the results of controlled feeding studies and clinical trials. Finally, we point out the possible physiological mechanisms through which MUFA and olive oil can reduce BP and prevent the development of HT.

\section{Dietary sources of MUFA}

MUFA are fatty acids with a single double bond in the molecule. The most abundant MUFA in the diet is oleic acid (C18:1n-9). Table 1 shows the foods with the highest amounts of $\mathrm{MUFA}^{7-9}$. In Mediterranean countries, the main source of MUFA in the diet is olive oil. Other important dietary sources of MUFA are nuts and some types of meat. In the USA and Northern Europe, meat is one of the main sources of MUFA ${ }^{10,11}$.

Virgin (non-refined) olive oil, besides its MUFA content, has important amounts of antioxidants and phytochemicals. However, when refined or heated to frying temperature in air, olive oil loses most of these non-lipidic natural compounds ${ }^{12}$.

Additionally, new oil variants, rich in oleic acid, have been developed in recent decades. Thus, high-oleic-acid sunflower, soybean, safflower, corn and peanut oils are available on the market ${ }^{9}$. Along with the high amount of MUFA achieved in these oil variants, another characteristic is their increased amount of $\alpha$-tocopherol.

\section{Epidemiological evidence}

Some epidemiological studies have assessed the relationship between types of dietary fat and incidence of HT or changes in BP (Table $2^{6,13-20}$ ). However, most of them have been conducted in the USA and Northern Europe, where overall MUFA consumption is only moderate and comes mainly from some types of meat, and hence is highly correlated with the intake of saturated fat. In fact, most epidemiological studies conducted outside Mediterranean countries have not found relevant associations between MUFA intake and the risk of HT.

An ecological analysis of NHANES III data (Third National Health and Nutritional Examination Survey) found a higher consumption of MUFA in regions with the highest mean $\mathrm{BP}^{21}$. Results from prospective studies show 
Table 1 Content of monounsaturated fatty acids (MUFA) in some foods

\begin{tabular}{lc}
\hline & MUFA $(\mathrm{g} / 100 \mathrm{~g})$ \\
\hline Oils & \\
Olive oil & 73.9 \\
Sunflower oil & 31.8 \\
High-oleic-acid sunflower oil & 83.6 \\
Safflower oil & 14.4 \\
High-oleic-acid safflower oil & 74.6 \\
Corn oil & 29.3 \\
Soybean oil & 24.3 \\
Canola oil & 58.9 \\
Peanut oil & 46.2 \\
Foods & \\
Peanuts & 23.4 \\
Hazelnuts & 42.2 \\
Almonds & 36.6 \\
Lard & 41.6 \\
Butter & 26.8 \\
\hline
\end{tabular}

Sources: Moreiras et al. ${ }^{7}$, US Department of Agriculture ${ }^{8}$, and MartínezForce and Garcés ${ }^{9}$.

similar results. In nearly 60000 US women included in the Nurses' Health Study, followed from 1980 to 1984, there was no relationship between total fat, saturated fat or unsaturated fat intake and the risk of $\mathrm{HT}^{13}$. A more recent analysis of the same cohort reached similar conclusions ${ }^{14}$. Similarly, the Health Professionals' Follow-up Study, analysing more than 30000 US men who were followed for 4 years, did not find any association between BP and intake of saturated, polyunsaturated or trans-unsaturated $\mathrm{fat}^{15}$. In the Chicago Western Electric Company Study, a cohort with nearly 1800 men followed up over 8 years, intakes of total fat, saturated fatty acids (SFA), polyunsaturated fatty acids (PUFA) and MUFA were positively and significantly related to average annual change in systolic $\mathrm{BP}^{16}$. Results from the Multiple Risk Factor Intervention Trial showed an inverse association of BP with PUFA intake and with the dietary PUFA/SFA ratio, but the authors did not report any association between MUFA and $\mathrm{BP}^{17}$. Only one small cross-sectional study conducted in 76 middle-aged American men showed an inverse relationship between BP and MUFA intake as assessed from 3-day food records ${ }^{18}$. All these studies adjusted their analyses for potential confounding factors, including other dietary exposures. Also, the prospective design in most of them precluded a reverse causation bias; i.e. that changes in diet may be derived from the previous knowledge of BP levels.

On the contrary, the few epidemiological studies conducted in Southern Europe show very different results, suggesting a protective role for MUFA or olive oil. The high proportion that meat represents as a major source of MUFA in Western diets may have hindered the ability of epidemiological studies conducted in the USA and Northern European countries to find a protective effect of MUFA on HT. Southern European countries, where a substantial proportion of the population still follows the traditional olive oil-rich Mediterranean diet, are the ideal setting to ascertain this association, thus avoiding the strong correlation between MUFA and meat intake. Investigators from the Italian Nine Communities Study assessed the relationship between olive oil consumption and $\mathrm{BP}$ in almost 5000 middle-aged non-hypertensive individuals. Results showed a statistically significant inverse association, both for systolic and diastolic BP, and for both men and women when analysed separately, in spite of the moderate quality of the dietary assessment (researchers used a qualitative food-frequency questionnaire with only 35 items) ${ }^{19}$. In this same study, PUFA were associated with lower systolic BP but had no effect on diastolic BP.

In Greece, the cradle of the Mediterranean diet concept, a cross-sectional analysis of 20343 EPIC (European Prospective Investigation into Cancer and Nutrition)

Table 2 Epidemiological studies assessing the relationship between monounsaturated fatty acids intake, olive oil consumption and hypertension

\begin{tabular}{|c|c|c|c|c|}
\hline Study & Country & Study design & Participants & Main results \\
\hline \multicolumn{5}{|c|}{ Studies conducted in non-Mediterranean countries } \\
\hline Nurses' Health Study ${ }^{13,14}$ & USA & Cohort & 58218 women aged $34-59$ years & No effect on risk of HT \\
\hline $\begin{array}{l}\text { Health Professionals' } \\
\text { Follow-up Study }{ }^{15}\end{array}$ & USA & Cohort & 30681 men aged $40-75$ years & No effect on risk of $\mathrm{HT}$ \\
\hline $\begin{array}{l}\text { Chicago Western Electric } \\
\text { Company Study }{ }^{16}\end{array}$ & USA & Cohort & 1714 men aged $40-55$ years & $\begin{array}{l}\text { MUFA directly associated with } \\
\text { increase in BP }\end{array}$ \\
\hline $\begin{array}{l}\text { Multiple Risk Factor } \\
\quad \text { Intervention Trial }^{17}\end{array}$ & USA & Cohort & 11342 men aged $35-57$ years & No effect on BP \\
\hline Williams et al..$^{18}$ & USA & Cross-sectional & 76 men aged $30-55$ years & $\begin{array}{l}\text { MUFA intake inversely associated } \\
\text { with BP levels }\end{array}$ \\
\hline \multicolumn{5}{|c|}{ Studies conducted in Mediterranean countries } \\
\hline $\begin{array}{l}\text { Italian Nine Communities } \\
\text { Study }{ }^{19}\end{array}$ & Italy & Cross-sectional & $\begin{array}{l}4903 \text { men and women } \\
\text { aged } 20-59 \text { years }\end{array}$ & $\begin{array}{l}\text { OO consumption inversely } \\
\text { associated with BP levels }\end{array}$ \\
\hline EPIC-Greece ${ }^{6}$ & Greece & Cross-sectional & $\begin{array}{l}20343 \text { men and women } \\
\text { aged } 20-86 \text { years }\end{array}$ & $\begin{array}{l}\text { OO consumption and MUFA/SFA ratio } \\
\text { inversely associated with BP levels }\end{array}$ \\
\hline SUN Study ${ }^{20}$ & Spain & Cohort & $\begin{array}{l}6863 \text { men and women } \\
\text { aged } 20-80 \text { years }\end{array}$ & $\begin{array}{l}\mathrm{OO} \text { associated with a reduced } \\
\text { risk of } \mathrm{HT} \text { among men but } \\
\text { not among women }\end{array}$ \\
\hline
\end{tabular}

EPIC - European Prospective Investigation into Cancer and Nutrition; SUN - Seguimiento Universidad de Navarra; HT - hypertension; MUFA - monounsaturated fatty acids; BP - blood pressure; OO - olive oil; SFA - saturated fatty acids. 
participants showed that the MUFA/SFA intake ratio was inversely associated with systolic and diastolic BP, after adjustment for potential confounders. Similarly, olive oil consumption was inversely associated with BP, even after adjustment for vegetable consumption ${ }^{6}$. For each $22 \mathrm{~g}$ increase in the daily consumption of olive oil, systolic and diastolic BP were 0.8 and $0.3 \mathrm{mmHg}$ lower, on average, after adjustments were made for sex, age, education, body mass index, waist-to-hip ratio, energy intake, physical activity and vegetable consumption.

Another study that has assessed the relationship between MUFA, olive oil and BP is the SUN (Seguimiento Universidad de Navarra) Study. This cohort study has been specifically designed to assess prospectively the effect of a Mediterranean dietary pattern on HT, diabetes, obesity and cardiovascular disease ${ }^{22}$. In a baseline assessment of the first 8800 participants in this cohort, MUFA intake was associated with a lower prevalence of HT among those individuals with low fruit and vegetable consumption, while this effect was not apparent among those with higher fruit and vegetable consumption ${ }^{23}$.

However, the three previous studies had a crosssectional design, with their problems in establishing causal relationships. More recently, a prospective analysis of the SUN Study showed that olive oil consumption was inversely associated with the risk of developing HT among $\operatorname{men}^{20}$, but no effect was observed among women. In this study, 5573 participants free of HT at baseline were followed up for a median of 28.5 months. Men in the highest quintile of olive oil consumption had a $50 \%$ reduction in the risk of incident HT compared with those in the lowest quintile of consumption, with a statistically significant linear trend $(P=0.02)$. This association was independent of other known risk factors for HT including relevant dietary factors. Among women, there was not a clear relationship probably due to a low number of incident cases of HT observed in the women of this cohort during that period. To our knowledge, this is the only study that has prospectively assessed the association between olive oil and the risk of HT. Information on diet and confounding factors was collected before the diagnosis of HT, and the analysis was adjusted for other factors potentially associated with the risk of HT. Its main drawback is the selfreported diagnosis of HT, although the validation study conducted in that population ${ }^{24}$ and the high educational level of the study participants guarantee to a fair extent the validity of the outcome information.

\section{Feeding trials}

Since the late 1980s, several feeding trials have examined in a controlled environment the effect of MUFA and olive oil on BP. A summary of their main characteristics, including the source of MUFA and their overall results, is presented in Table $3^{25-35}$. In general, these studies were conducted in very controlled environments, with tight monitoring of the diets to which participants were allocated, leading to a sharp contrast between the dietary profiles of compared groups. Additionally, none of them was funded by the olive oil industry. Only two of them reported that the oils they used to feed participants were provided by oil companies ${ }^{30,31}$.

One of the earliest studies was conducted in Italy on 57 normotensive volunteers aged 30 to 50 years. These individuals underwent a dietary intervention with a $70 \%$ increase in energy from SFA and a corresponding decrease in MUFA and carbohydrates. After 6 weeks, a significant increase in systolic and average BP was observed. BP reverted to baseline values when participants returned to their usual diet ${ }^{36}$. However, it was not possible to separate changes in BP derived from decreases in MUFA intake or from other dietary changes.

In a study conducted in Spain, 42 subjects were fed two different diets during 5 -week periods. Diets differed in their fatty acid composition, while energy intake from carbohydrate, proteins and fat was held constant. Compared with a diet rich in SFA (17\% of total energy intake), an olive oil-enriched diet (21\% of total energy intake from MUFA) was associated with lower levels of mean $\mathrm{BP}^{30}$. A similar study, conducted in 41 male young volunteers, showed that a diet rich in MUFA (22\% of total energy intake), from olive oil, had a beneficial effect on glucose metabolism and BP compared with a diet rich in SFA or carbohydrate ${ }^{31}$.

Similarly, Thomsen et al. observed that an olive oilrich diet (30\% of total energy intake from MUFA) administered during 3 weeks significantly reduced systolic and diastolic BP compared with a PUFA-rich diet (27\% of total energy intake) in a group of 16 normotensive type 2 diabetics ${ }^{28}$. This same group reported a beneficial effect of an olive oil-enriched diet compared with a high-carbohydrate $\operatorname{diet}^{26}$. Another study in 47 healthy normotensive volunteers showed a reduction of $\mathrm{BP}$ after a diet with a high amount of MUFA, from olive oil, compared with a diet rich in SFA. However, in this case, the MUFA diet did not perform better than a high-carbohydrate $\operatorname{diet}^{25}$. In women with gestational diabetes, MUFA (from high-oleic sunflower oil) intake prevented the $\mathrm{BP}$ increase in the third trimester of pregnancy compared with a diet rich in carbohydrates $^{34}$

Ferrara et al. reported that a diet rich in extra virgin olive oil was associated with a reduced need for antihypertensive medication compared with a diet enriched in sunflower oil $^{32}$. In this randomised cross-over trial, 23 hypertensive patients were assigned to each diet over periods of 6 months. Compared with the sunflower oil diet, the olive oil diet reduced significantly both systolic and diastolic BP $(-8 \mathrm{mmHg}$ and $-6 \mathrm{mmHg}$, respectively). Daily drug dosage was significantly reduced during 


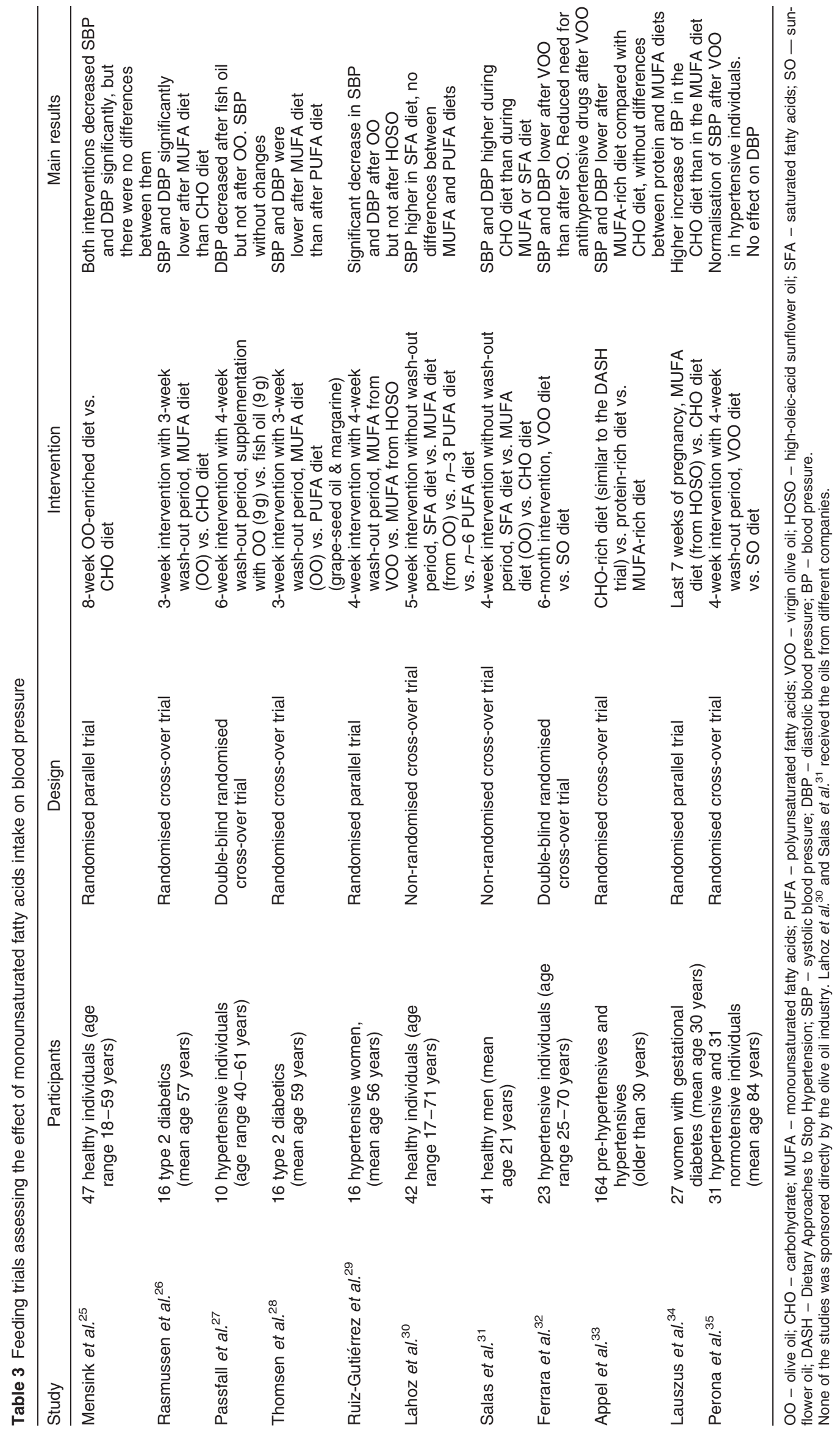


the olive oil diet but not with the sunflower oil diet (approximately 50\% vs. 4\% reduction). This study suggests that olive oil can be used as a non-pharmacological approach in the treatment of HT.

More recently, the OmniHeart cross-over randomised trial compared the effect of three different diets on BP, a CHO-rich DASH (Dietary Approaches to Stop Hypertension) diet, a protein-rich diet and a MUFA-rich diet, in a group of 164 adults older than 30 years with prehypertension or stage $1 \mathrm{HT}$. After 6 weeks, the proteinand MUFA-rich diets produced higher reductions in BP than the $\mathrm{CHO}$ diet. However, there were no differences between the MUFA- and protein-rich diets ${ }^{33}$.

It has been hypothesised that the effect of olive oil on BP is not only mediated through its MUFA content. Other compounds, such as the polyphenols present in virgin olive oil, can have a favourable effect. To assess this hypothesis, some studies have compared the effect of olive oil and high-oleic-acid sunflower oil on BP, both with a similar content in MUFA. Ruiz-Gutiérrez et al. reported a reduction in both systolic and diastolic BP after an olive oil-rich diet but not after a high-oleic-acid sunflower oil $\operatorname{diet}^{29}$.

Not all studies have shown a beneficial effect on BP from MUFA or olive oil intake. For example, Perona et al. showed that a diet enriched with $60 \mathrm{~g}$ of virgin olive oil, compared with $60 \mathrm{~g}$ of sunflower oil, daily for 4 weeks, reduced systolic but not diastolic BP in a group of 31 hypertensives, with no effect on 31 normotensive individuals $^{35}$. In the same way, fish oil but not olive oil was effective in the reduction of diastolic BP in a crossover study on 10 hypertensive subjects $(9 \mathrm{~g}$ fish oil or $9 \mathrm{~g}$ olive oil daily for 6 weeks) ${ }^{27}$. Another study conducted in 44 male mild hypertensives showed that systolic BP during psychophysiological stress was significantly lower after a diet enriched in sunflower oil $(60 \mathrm{ml}$ daily for 2 weeks), but not after olive oil or linseed oil supplementation (same amount for the same time) ${ }^{37}$.

Canola oil is also rich in MUFA. Some animal studies have assessed its effect on BP. In general, the results do not show an important beneficial effect of this vegetable oil on $\mathrm{BP}^{38,39}$. On the contrary, rats fed diets rich in canola oil lived a shorter time than rats fed with PUFA-enriched $\operatorname{diets}^{40,41}$. To our knowledge, the only feeding trial conducted in human subjects did not find any significant effect for a diet enriched with canola oil on BP compared with a diet enriched with sunflower oil ${ }^{42}$. Similarly, with the exception of the studies that have used high-oleic-acid sunflower oil, there is no evidence in humans that MUFArich oils other than olive oil have a favourable impact on BP.

We can summarise this evidence as follows: although there are some inconsistencies, MUFA from vegetable sources, especially from olive oil in the context of Mediterranean diets, can be beneficial in the management of HT and probably may play a role in the primary prevention of this disorder.

\section{Physiological mechanisms}

The mechanisms through which MUFA and olive oil could modify BP levels are not completely clear. In the first place, although the number of studies is scarce, it seems that a high MUFA intake modifies membrane phospholipids in a way ${ }^{43,44}$ that can, in turn, alter BP regulation and lead to lower levels of $\mathrm{BP}^{29}$. In fact, a recent study has shown that a molecule derived from oleic acid, 2hydroxyoleic acid, has an impressive antihypertensive effect $^{45}$. The authors of this study observed that the effect could be mediated through the modification of membrane proteins.

Results from the Pizarra Study ${ }^{46}$ have suggested another explanation for the possible beneficial effect of MUFA on BP. In this study, the amount of polar compounds in cooking oil, resulting from the degradation of vegetable oils during the cooking process, was directly associated with BP levels. Interestingly, the utilisation of olive oil as cooking oil reduced the formation of these polar compounds. Moreover, olive oil consumption was directly associated with the MUFA content of plasma phospholipids. This, in turn, was inversely associated with BP levels.

Polyphenols present in olive oil, such as oleuropein, hydroxytyrosol, tyrosol and caffeic acid, have an important antioxidant effect. In rat leucocytes, these molecules have been shown to inhibit leukotriene B4 generation at the 5-lipoxygenase level and to reduce the generation of reactive oxygen species ${ }^{47}$ - these later molecules causing endothelial dysfunction, a process that has been implicated in the pathophysiology of $\mathrm{HT}^{48}$. Finally, vascular response to a hypertensive stimulus was reduced in rats fed virgin olive oil but not high-oleic-acid sunflower oil, suggesting additional effects of olive oil beyond its MUFA composition ${ }^{49}$. These mechanistic findings of a beneficial effect due to the non-lipidic fraction of olive oil fit well with the epidemiological evidence that supports a major benefit associated not with all MUFA, but specifically with MUFA derived from olive oil (studies conducted in Mediterranean countries) and even more for virgin olive oil, rich in polyphenols.

Finally, several studies have assessed the effect of a MUFA-rich diet on endothelial function, mainly by way of evaluating flow-mediated dilation. Results regarding the acute postprandial effects of these diets have been inconclusive. MUFA intake worsened flow-mediated dilation $^{50}$ in some cases, had no effect ${ }^{51,52}$ or improved endothelial function ${ }^{53}$. Interestingly, in the only study where MUFA had an acute adverse impact on endothelial function, this harmful effect was cancelled out when olive oil, as the source of MUFA, was consumed with foods (balsamic vinegar and salad), which is the usual way of olive oil consumption in Mediterranean countries ${ }^{50}$. Moreover, in the long term, diets rich in olive oil have shown an improvement in endothelial function compared with a high-carbohydrate diet ${ }^{54}$ or a high-linoleic-acid diet ${ }^{55}$. 
In conclusion, there is laboratory and epidemiological evidence to suggest that MUFA, and particularly olive oil, could be components of a diet with some potential to be recommended for the prevention of HT. The results presented here suggest that adherence by the population at large to a Mediterranean dietary pattern, with an abundant supply of virgin olive oil, might reduce the overall prevalence of HT in Western societies, with important consequences for public health nutrition. None the less, results from prospective studies at a population level and primary prevention trials are needed before we can firmly recommend olive oil in the primary prevention of HT.

\section{Acknowledgements}

This work was partially funded by the Spanish Ministry of Health (Fondo de Investigaciones Sanitarias, project G03/140, Red Tematica de Dieta y Enfermedad Cardiovascular). A.A. was partially supported by a Fulbright fellowship and by an MMA Foundation for Medical Research grant. We are grateful to our dietitian, Ms Carmen de la Fuente, for her nutritional advice in the preparation of the manuscript. There is no conflict of interest. This study has not received any funding from the olive oil industry.

\section{References}

1 Hermansen K. Diet, blood pressure and hypertension. British Journal of Nutrition 2000; 83: S113-9.

2 Reddy KS, Katan MB. Diet, nutrition and the prevention of hypertension and cardiovascular diseases. Public Health Nutrition 2004; 7: 167-86.

3 Whelton PK, He J, Appel LJ, Cutler JA, Havas S, Kotchen TA, et al.; National High Blood Pressure Education Program Coordinating Committee. Primary prevention of hypertension: clinical and public health advisory from the National High Blood Pressure Education Program. Journal of the American Medical Association 2002; 288: 1882-8.

4 Appel LJ, Moore TJ, Obarzanek E, Vollmer WM, Svetkey LP, Sacks FM, et al. A clinical trial of the effects of dietary patterns on blood pressure. DASH Collaborative Research Group. New England Journal of Medicine 1997; 336 $1117-24$

5 Martínez-González MA, Sánchez-Villegas A. The emerging role of Mediterranean diets in cardiovascular epidemiology: monounsaturated fats, olive oil, red wine or the whole pattern? European Journal of Epidemiology 2004; 19: 9-13.

6 Psaltopoulou T, Naska A, Orfanos P, Trichopoulos D, Mountokalakis T, Trichopoulou A. Olive oil, the Mediterranean diet, and arterial blood pressure: the Greek European Prospective Investigation into Cancer and Nutrition (EPIC) study. American Journal of Clinical Nutrtion 2004; 80: 1012-8.

7 Moreiras O, Carbajal A, Cabrera L, Cuadrado C. Tablas de Composición de Alimentos, 7th ed. Madrid: Pirámide, 2003.

8 US Department of Agriculture, Agricultural Research Service. USDA National Nutrient Database for Standard Reference, Release 17 [online]. Available at http://www.nal.usda.gov/ fnic/foodcomp. Accessed 21 May 2005.

9 Martínez-Force E, Garcés R. New varieties with modified fatty acid composition in the oil. Trends in Agronomy 1999; 2: $13-21$.
10 Hulshof KFAM, van Erp-Baart MA, Anttolainen M, Becker W, Church SM, Couet C, et al. Intake of fatty acids in Western Europe with emphasis on trans fatty acids: the TRANSFAIR study. European Journal of Clinical Nutrition 1999; 53: $143-57$.

11 Nicklas TA, Hampl JS, Taylor CA, Thompson VJ, Heird WC. Monounsaturated fatty acid intake by children and adults: temporal trends and demographic differences. Nutrition Reviews 2004; 62: 132-41.

12 Ros E. Dietary cis-monounsaturated fatty acids and metabolic control in type 2 diabetes. American Journal of Clinical Nutrition 2003; 78: 617S-25S.

13 Witteman JCM, Willett WC, Stampfer MJ, Colditz GA, Sacks FM, Speizer FE, et al. A prospective study of nutritional factors and hypertension among US women. Circulation 1989; 80: $1320-7$.

14 Ascherio A, Hennekens CH, Willett WC, Sacks F, Rosner B, Manson J, et al. Prospective study of nutritional factors, blood pressure, and hypertension among US women. Hypertension 1996; 27: 1065-72.

15 Ascherio A, Rimm EB, Giovannucci EL, Colditz GA, Rosner B, Willett WC, et al. A prospective study of nutritional factors and hypertension among US men. Circulation 1992; 86: $1475-84$.

16 Stamler J, Liu K, Ruth KJ, Pryer J, Greenland P. Eight-year blood pressure change in middle-aged men: relationship to multiple nutrients. Hypertension 2002; 39: 1000-6.

17 Stamler J, Caggiula A, Grandits GA, Kjelsberg M, Cutler JA. Relationship to blood pressure of combinations of dietary macronutrients: findings of the Multiple Risk Factor Intervention Trial (MRFIT). Circulation 1996; 94: 2417-23.

18 Williams PT, Fortmann SP, Terry RB, Garay SC, Vranizan KM, Ellsworth $\mathrm{N}$, et al. Associations of dietary fat, regional adiposity, and blood pressure in men. Journal of the American Medical Association 1987; 257: 3251-6.

19 Trevisan M, Krogh V, Freudenheim J, Blake A, Muti P, Panico $\mathrm{S}$, et al. Consumption of olive oil, butter, and vegetable oils and coronary heart disease risk factors. The Research Group ATS-RF2 of the Italian National Research Council. Journal of the American Medical Association 1990; 263: 688-92.

20 Alonso A, Martínez-González MA. Olive oil consumption and reduced incidence of hypertension: the SUN Study. Lipids 2004; 39: 1233-8.

21 Hajjar I, Kotchen T. Regional variations of blood pressure in the United States are associated with regional variations in dietary intakes: The NHANES-III data. Journal of Nutrition 2003; 133: 211-4.

22 Martínez-González MA, Sánchez-Villegas A, de Irala-Estévez J, Martí A, Martínez JA. Mediterranean diet and stroke: objectives and design of the SUN Project. Nutritional Neuroscience 2002; 5: 65-73.

23 Alonso A, de la Fuente C, Martín-Arnau AM, de Irala J, Martínez JA, Martínez-González MA. Fruit and vegetable consumption is inversely associated with blood pressure in a Mediterranean population with a high vegetable-fat intake: the Seguimiento Universidad de Navarra (SUN) Study. British Journal of Nutrition 2004; 92: 311-9.

24 Alonso A, Beunza JJ, Delgado-Rodríguez M, MartínezGoxález MA. Validation of self reported diagnosis of hypertension in a cohort of university graduates in Spain. BMC Public Health 2005; 5: 94.

25 Mensink RP, Janssen MC, Katan MB. Effect on blood pressure of two diets differing in total fats but not in saturated and polyunsaturated fatty acids in healthy volunteers. American Journal of Clinical Nutrition 1988; 47: 976-80.

26 Rasmussen OW, Thomsen C, Hansen KW, Vesterlund M, Winther E, Hermansen K. Effects on blood pressure, glucose, and lipid levels of a high-monounsaturated fat diet compared with a high-carbohydrate diet in NIDDM subjects. Diabetes Care 1993; 16: 1565-71. 
27 Passfall J, Philipp T, Woermann F, Quass P, Thiede M, Haller H. Different effects of eicosapentaenoic acid and olive oil on blood pressure, intracellular free platelet calcium, and plasma lipids in patients with essential hypertension. Clinical Investigation 1993; 71: 628-33.

28 Thomsen C, Rasmussen OW, Hansen KW, Vesterlund M, Hermansen K. Comparison of the effects on the diurnal blood pressure, glucose, and lipid levels of a diet rich in monounsaturated fatty acids with a diet rich in polyunsaturated fatty acids in type 2 diabetic subjects. Diabetic Medicine 1995; 12: 600-6.

29 Ruiz-Gutiérrez V, Muriana FJ, Guerrero A, Cert AM, Villar J. Plasma lipids, erythrocyte membrane lipids and blood pressure of hypertensive women after ingestion of dietary oleic acid from two different sources. Journal of Hypertension 1996; 14: 1483-90.

30 Lahoz C, Alonso R, Ordovas JM, López-Farre A, de Oya M, Mata P. Effects of dietary fat saturation on eicosanoid production, platelet aggregation and blood pressure. European Journal of Clinical Investigation 1997; 27: 780-7.

31 Salas J, López Miranda J, Jansen S, Zambrana JL, Castro P, Paniagua JA, et al. La dieta rica en grasa monoinsaturada modifica de forma beneficiosa el metabolismo de los hidratos de carbono y la presión arterial. Medicina Clinica 1999; 113: 765-9.

32 Ferrara LA, Raimondi AS, d'Episcopo L, Guida L, Dello Russo A, Marotta T. Olive oil and reduced need for antihypertensive medications. Archives of Internal Medicine 2000; 160: $837-42$.

33 Appel LJ, Sacks FM, Carey VJ, Obarzanek E, Swain JF, Miller ER III. et al. Effects of protein, monounsaturated fat, and carbohydrate intake on blood pressure and serum lipids. Results of the OmniHeart Randomized Trial. Journal of the American Medical Association 2005; 294: 2455-64.

34 Lauszus FF, Rasmussen OW, Henriksen JE, Klebe JG, Jensen L, Lauszus KS, et al. Effect of a high monounsaturated fatty acid diet on blood pressure and glucose metabolism in women with gestational diabetes mellitus. European Journal of Clinical Nutrition 2001; 55: 436-43.

35 Perona JS, Cañizares J, Montero E, Sánchez-Dóminguez JM, Catalá A, Ruiz-Gutiérrez V. Virgin olive oil reduces blood pressure in hypertensive elderly subjects. Clinical Nutrition 2004; 23: 1113-21.

36 Strazzullo P, Ferro-Luzzi A, Siani A, Scaccini C, Sette S, Catasta $G$, et al. Changing the Mediterranean diet: effects on blood pressure. Journal of Hypertension 1986; 4: 407-12.

37 Singer P, Jaeger W, Berger I, Barleben H, Wirth M, RichterHeinrich E, et al. Effects of dietary oleic, linoleic and $\alpha$-linolenic acids on blood pressure, serum lipids, lipoproteins and the formulation of eicosanoid precursors in patients with mild essential hypertension. Journal of Human Hypertension 1990; 4: 227-33.

38 Naito Y, Nagata T, Takano Y, Nagatsu T, Ohara N. Rapeseed oil ingestion and exacerbation of hypertension-related conditions in stroke prone spontaneously hypertensive rats. Toxicology 2003; 187: 205-16.

39 Aguila MB, Sa Silva SP, Pinheiro AR, Mandarim-de-Lacerda CA. Effects of long-term intake of edible oils on hypertension and myocardial and aortic remodelling in spontaneously hypertensive rats. Journal of Hypertension 2004; 22: $921-9$.

40 Huang MZ, Watanabe S, Kobayashi T, Nagatsu A, Sakakibara J, Okuyama H. Unusual effect of some vegetable oils on the survival time of stroke-prone spontaneously hypertensive rats. Lipids 1997; 32: 745-51.

41 Ratnayake WM, Plouffe L, Hollywood R, L'Abbe MR, Hidiroglou N, Sarwar G, et al. Influence of sources of dietary oils on the life span of stroke-prone spontaneously hypertensive rats. Lipids 2000; 35: 409-20.

42 Mutanen M, Kleemola P, Valsta LM, Mensink RP, Rasanen L. Lack of effect on blood pressure by polyunsaturated and monounsaturated fat diets. European Journal of Clinical Nutrition 1992; 46: 1-6.

43 Pagnan A, Corrocher R, Ambrosio GB, Ferrari S, Guarini P, Piccolo D, et al. Effects of an olive oil-rich diet on erythrocyte membrane lipid composition and cation transport systems. Clinical Science 1989; 76: 87-93.

44 Corrocher R, Pagnan A, Ambrosio GB, Ferrari S, Olivieri O, Guarini $\mathrm{P}$, et al. Effects induced by olive oil-rich diet on erythrocytes membrane lipids and sodium-potassium transports in postmenopausal hypertensive women. Journal of Endocrinological Investigation 1992; 15: 369-76.

45 Alemany R, Terés S, Baamonde C, Benet M, Vögler O, Escribá PV. 2-Hydroxyoleic acid: a new hypotensive molecule. Hypertension 2004; 43: 249-54.

46 Soriguer F, Rojo-Martínez G, Dobarganes MC, Garcia Almeida JM, Esteva I, Beltran M, et al. Hypertension is related to the degradation of dietary frying oils. American Journal of Clinical Nutrition 2003; 78: 1092-7.

47 de la Puerta R, Ruiz-Gutiérrez V, Hoult JRS. Inhibition of leukocyte 5-lipoxygenase by phenolics from virgin olive oil. Biochemical Pharmacology 1999; 57: 445-9.

48 Cai H, Harrison DG. Endothelial dysfunction in cardiovascular diseases: the role of oxidant stress. Circulation Research 2000; 87: 840-4.

49 Herrera MD, Pérez-Guerrero C, Marhuenda E, RuizGutiérrez V. Effects of dietary oleic-rich oils (virgin olive and high-oleic-acid sunflower) on vascular reactivity in Wistar-Kyoto and spontaneously hypertensive rats. British Journal of Nutrition 2001; 86: 349-57.

50 Vogel RA, Corretti MC, Plotnick GD. The postprandial effect of components of the Mediterranean diet on endothelial function. Journal of the American College of Cardiology 2000; 36: 1455-60.

51 Ong PJL, Dean TS, Hayward CS, Della Monica PL, Sanders TAB, Collins P. Effect of fat and carbohydrate consumption on endothelial function. Lancet 1999; 354: 2134.

52 Williams MJA, Sutherland WHF, McCormick MP, Yeoman D, de Jong SA, Walker RJ. Normal endothelial function after meals rich in olive oil or safflower oil previously used for deep frying. Nutrition, Metabolism, and Cardiovascular Diseases 2001; 11: 147-52.

53 West SG, Hecker KD, Mustad VA, Nicholson S, Schoemer SL, Wagner $\mathrm{P}$, et al. Acute effects of monounsaturated fatty acids with and without omega-3 fatty acids on vascular reactivity in individuals with type 2 diabetes. Diabetologia 2005; 48 : 113-22.

54 Fuentes F, López-Miranda J, Sanchez E, Sanchez F, Paez J, Paz-Rojas E, et al. Mediterranean and low-fat diets improve endothelial function in hypercholesterolemic men. Annals of Internal Medicine 2001; 134: 1115-9.

55 Ryan M, McInerney D, Owens D, Collins P, Johnson A, Tomkin GH. Diabetes and the Mediterranean diet: a beneficial effect of oleic acid on insulin sensitivity, adipocyte glucose transport and endothelium-dependent vasoreactivity. Quarterly Journal of Medicine 2000; 93: 85-91. 